\title{
Watershed Sustainability Index Development and Application: Case Study of the Motru River in Romania
}

\author{
Oana Mititelu-Ionuş* \\ Department of Geography, Faculty of Sciences, University of Craiova, \\ 13 A.I. Cuza St., Craiova 200585, Romania
}

Received: 18 February 2017

Accepted: 28 March 2017

\begin{abstract}
The present study hypothesis resulted in the identification of a viable system of indicators that might play an important role in the measurement of sustainable development. The main purpose of our research is the development of a watershed sustainability index and its application for the Motru River basin. This catchment area covers an area of $1,895 \mathrm{~km}^{2}$ within southwestern Romania. Applying the watershed sustainability index was based on the equal weighting scheme in order to aggregate the parameters (water availability per capita, variation of BOD, variation in the ratio of the agricultural area and the urban population, life quality index, and education index). Considering that basin management is a dynamic and holistic process, the state-pressure-response model was applied to the four components in a matrix scheme. As a result, for the Motru River basin, the obtained values of the watershed sustainability index were: 0.36 for five years and 0.51 for 10 years. The indicators with the lowest scores were hydrology and policy-education $(0.17)$, while the environment indicator scored the highest (0.75). Applied to different time intervals, the watershed sustainability index emphasizes the evolution of watershed sustainability in order to help stakeholders and water managers in the decision-making process.
\end{abstract}

Keywords: sustainability, indicators, watershed, the Motru River

\section{Introduction}

International and National Framework

The first definition of sustainable development was proposed by the Brundtland report, which defined it as "Development that meets the needs of the present without compromising the ability of future generations

*e-mail: oana_ionus@yahoo.com to meet their own needs" [1]. Following the definitions for sustainable development, many tools aim to evaluate environmental, social, and economic aspects of the system [2-4]. Classically, it is considered that sustainable development has at least three dimensions: environmental (emphasizing the degradation of natural resources for human use), social (highlighting the unequal distribution of wealth and poverty), and economic (stating that any development meant to achieve sustainability needs to manage different capital flows) [5-6]. Subsequently, institutional dimension, which focuses on peace and security, has been added [7-8]. 
A detailed study of sustainable water management should be completed on a regional scale to provide the most relevant information for management and policy purposes [9-11]. Mays [12] emphasizes three domains of integrated water resource management, which include scope, scale, and governance. Two challenges of integrating the existing natural system and the social system data are worth being considered: one concerns the influence of environmental attitudes and water quality on water conservation efforts [13].

Sustainability indicators of river basins are different from traditional indicators of economic, social, and environmental progress. Therefore, many indices have been developed at a global level to achieve sustainable and integrated water management: the water poverty index (WPI) [14], the Canadian water sustainability index (CWSI) [15], the watershed sustainability index (WSI) [16], the West Java water sustainability index (WJWSI) [17], and the linear system of action [18]. An index of sustainability of water resources can be used as a tool to identify all factors that contribute to the improvement of water resources [19]. Liverman et al. [20] suggests the following characteristics for the selection of indicators: sensitive to changes in time, sensitive to changes across space or within groups, predictive or anticipatory, reference or threshold values available, and integrative.
In Romania, the quantification of sustainable development is made at administrative levels (national, regional, and local), but it lacks correlation with water resources and the analysis at the level of the river basin. Although between 1980 and 2007 the value of the human development index increased to 0.051 (6.5\%), Romania is situated in one of the lowest European positions in terms of human development according to the United Nations Development Program approach [21]. Between 1990 and 2012, the Romanian HDI value increased from 0.706 to 0.786 , an increase of $11 \%$, or an average annual increase of about $0.5 \%$ [22]. Position 55 that Romania occupied in 2012 (out of a total of 187 countries), as far as HDI value is concerned, is a modest position and suggests a weak recovery of the development potential in our country. The Romanian particularities related to territorial development also result from the fact that the country has the largest share of rural population in the European Union ( $45 \%$ of the population lives in villages). This means that some indicators such as unemployment are diminished because a large part of the population (about one third) works in agriculture, specifically under the conditions of subsistence agriculture [23].

Romanian studies regarding sustainable development at regional and local levels defines an analyses of this concept from a geographical and environmental point of view on the one hand [24-27], and from a statistical a)

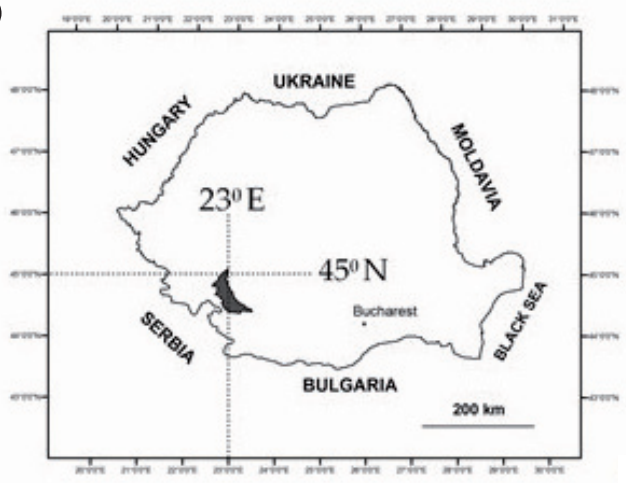

b)

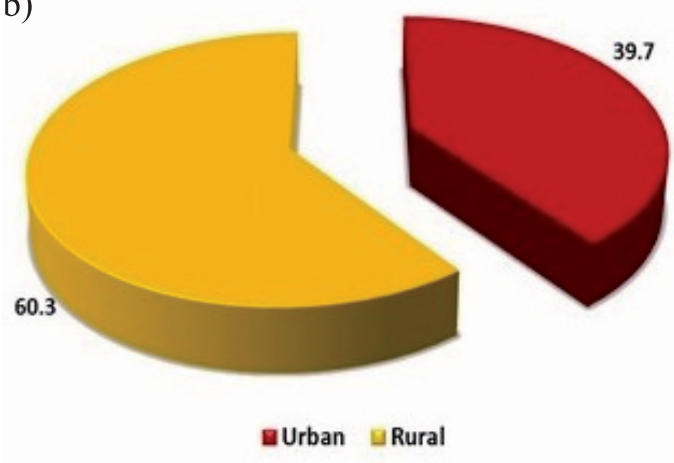

c)

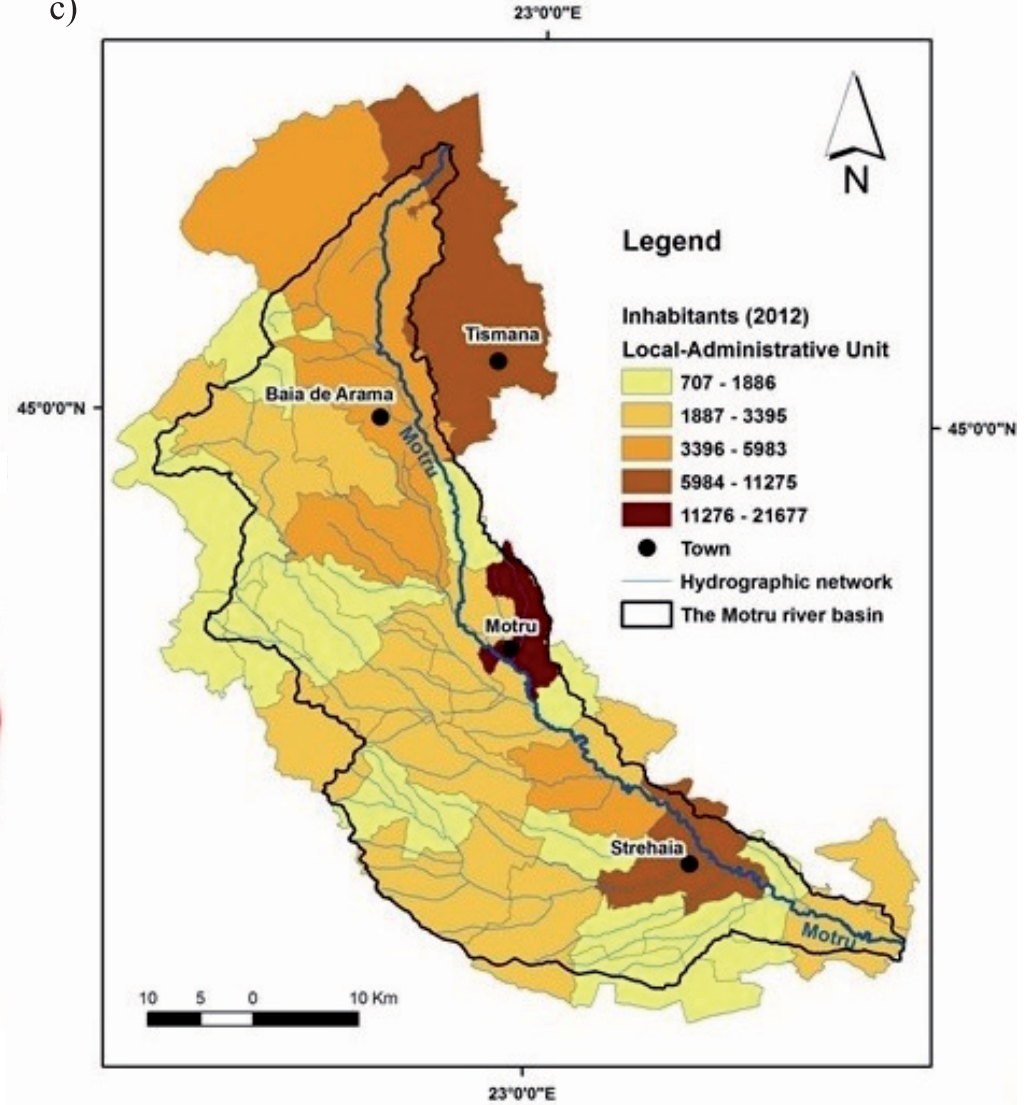

Fig. 1. The Motru River basin features: a) location, b) urban and rural populations (percentages), and c) demography and hydrographic network. 
and territorial point of view on the other [28-30]. "Water problems" are fundamentally human problems [31-32]. In this respect, the algorithm uses selected indicators reflecting the density of population, its dynamics and migratory increase, elder population, birth rate, unemployment, share of population working in agriculture, the number of people who completed a high school education, and inhabited area per person [30]. The difference is that at the micro-level (the Ialomița River basin and Bucharest urban area, for example), the numbers and types of indicators vary according to the peculiarity of geographical areas [26, 29].

In this regard, the study focuses on the integration of the socio-economic and natural resource aspects for use in integrated water resource management within the Motru River basin. Also considered will be a framework for developing an adaptable WSI; identifying components and indicators; justifying the selection of components; setting the values of state parameters, pressure, and response based on the level and score value classes; and interpreting and correlating the obtained values with the major disruptive factors. Thus, there will be proposed viable solutions to ensure sustainability at the river basin level.

\section{Study Area}

The Motru River $(134 \mathrm{~km})$ is situated in southwestern Romania, covering an area of $1,895 \mathrm{~km}^{2}$ [33]. Within its basin, the Motru receives 13 tributaries and forms a hydrographic network with a length of $670 \mathrm{~km}$ and a density of $0.36 \mathrm{~km} / \mathrm{km}^{2}$ (data processed after The Cadastral Atlas of Waters [34]) (Fig. 1).

The annual average flow of the Motru and its tributaries is $6.12 \mathrm{~m}^{3} / \mathrm{s}$, the value being registered at Fața Motrului hydrometric station, which closes the catchment area near where the Motru flows into the Jiu River [35].

Human pressure over the surface waters within the Motru basin is induced by the total number of inhabitants, the total number of inhabitants from urban areas (Motru, Strehaia, and Baia de Aramă), the generated organic charge, industrial activities (the extraction and preparation of inferior coal), land use (48.1\% of agricultural areas within the basin [36]), animal husbandry (the value class of 0.2-0.5 equivalent bovines/ha of agricultural land characterizes most of the catchment area), and, finally, by the degree of improvement of the hydrographic network (9.85\% hydro-technical works of the total $\mathrm{km}$ of the hydrographic network [37]).

In the Motru basin, the population is mostly rural, as there are 30 villages and only four towns. According to the demographic data provided by the National Institute of Statistics for 2002-12, we can speak about a decline in the number of inhabitants from 125,710 (2002) to 116,375 (2012) (Fig. 1). The distribution of population by age groups in the analyzed area is characteristic of Romanian society, respectively a structure that shows rapid aging [38]; in all villages of the studied area at least a quarter of the population is older than 60 .

\section{Materials and Methods}

\section{Research Methods}

The necessity of the indicators system at the local level consists first in its utility in rounding development strategies - strategies upon which the affirmation of local policies is based [28]. The quantification of sustainable development may be achieved both by using a punctual indicators system oriented toward various problems, as well by using synthetic, aggregated indicators that convey the level of sustainable development by a single numerical expression. The watershed sustainability index is calculated according to the formula (Eq. 1) [16, 39]:

$$
\mathrm{WSI}=(\mathrm{H}+\mathrm{E}+\mathrm{L}+\mathrm{P}) / 4
$$

This is used as a weighted mean as each indicator presents the same importance [16]. Status, pressures, and responses for each of these indicators are identified and labelled as parameters [40-41]. For the aggregation of the final index, all the indicators (hydrology, environment, life and policy) are brought to values between 0 and 1 . In applying this formula, the indicator policy in education index will be applied and the life indicator will refer to both education and living conditions. According to Chaves and Alipaz [16], in the case of the hydrology indicator there are two sets of parameters: one in relation to water quantity and the other to water quality. In case of water quantity, the parameter is the water availability per capita per year, considering surface waters. In case of water quality, since biochemical oxygen demand (BOD5, in $\mathrm{mg} / \mathrm{l}$ ) information is often available in watersheds and is correlated with other important water quality parameters, it was selected as a quality parameter [42].

Environment pressure index (EPI) is estimated as being the average variation of the basin agricultural area and urban population (in percent), in the studied period (Eq. 2) [43]:

\section{$\mathrm{EPI}=(\%$ variation of the basin agricultural area $+\%$ variation of the basin urban population) $/ 2$}

EPI can be positive, negative, or zero. Positive values indicate higher pressure over the remaining natural vegetation of the basin (environmental state).

In order to determine life and policy indicators as components of WSI within the Motru basin, it was decided to determine life quality index and education index based on the methodology proposed by Lazăr and Lazăr [28], which means modifying the used sub-indicators given that the water resource is mainly pointed at in the analysis of WSI. The concerns for quality of basic data include their relevance, accuracy, timeliness, accessibility, interpretability, and coherence. The sub-indicator composites chosen in calculating the life quality index 
are: medical units, medical staff, employees, delivered drinking water (thousands of $\mathrm{m}^{3} /$ year), wastewater treatment plants, and length of sewage network. The subindicator composites chosen in establishing the education index are: schools, teaching staff, pupils and students, libraries, and number of PCs. The values of the subindicators are calculated by comparing the real values (the value registered in 2007 for five-year analysis and the one in 2012 for a 10-year analysis) with the maximum and minimum values recorded in the analyzed period (Eq. 3) $[16,22]$ :

$$
\mathrm{X}_{\mathrm{j}}=\left(\mathrm{x}_{\mathrm{i}}-\mathrm{x}_{\text {min }}\right) /\left(\mathrm{x}_{\text {max }}-\mathrm{x}_{\text {min }}\right)
$$

...where $x_{i}$ is the effective value of the indicator (LAU2 value for the years 2002, 2007, and 2012), $x_{\text {min }}$ and $x_{\text {max }}$ are the minimum and maximum values for the entire period 2002-12, at county level with the separation of urban and rural LAU2.

Taking into account the same proposed weight [44] for all the components, life quality index and education index will be calculated like a weighted average (Eq. 4):

$$
I_{j}=\Sigma X_{j} / a_{j}
$$

... where $\mathrm{a}_{\mathrm{j}}$ is the number of the considered sub-indicators and $X_{j}$ is the individual sub-indicators value.

The final result for the two indices is expressed also as a value between 0 and 1 .

\section{Data Sources}

In order to meet the needs of the methods, information on life quality and education level was collected from the official websites of the National Institute of Statistics and County Statistics Offices [45]. Data concerning the discharge and water quality were collected from the Jiu River Basin Management Plan [35] - the online official report of the Jiu Water Branch. As time is relevant in the subsequent impacts on the environment, the research focused on two periods: the first studied period was five years, between 2002 and 2007, and the second period was 10 years, between 2002 and 2012, as environmental and demographic data were available. The maps were produced by overlapping the sub-indicator data based on spatial and temporal dynamics on the scale of the Motru River basin (2002, 2007, and 2012).

\section{Results and Discussion}

Hydrology Indicator: Development and Application

\section{Water Quantity Sub-Indicator}

The determination of the values of the three parameters related to the sustainability phases (state, pressure and response) was achieved by following the steps described below. State - basin water availability per capita $\left(\mathrm{m}^{3} /\right.$ person year), taking into account surface water resources, was established based on the annual average flow of the Motru river recorded at Fața Motrului hydrometric station that closes the entire catchment area. The value of multiannual average flow (for 5 years - from 2002 to 2007, respectively 10 years - from 2002 to 2012) was multiplied with the number of seconds in a year and then divided by the number of inhabitants in 2007 and 2012, respectively.

Pressure - $\Delta 1$-variation in the basin water availability per capita in the studied period related to the long term average represents the water availability in 2012 and 2007 at the initial considered phase, namely 2002, making the difference between the amounts. The resulting difference is expressed as a percentage based on long-term average (annual average flow) that is considered as being $100 \%$ and the resulted percentage fits in a score according to the corresponding level. The long-term value for the basin water availability per capita $\left(2,662.66 \mathrm{~m}^{3} /\right.$ person year $)$ is calculated according to the average values of flow and population in the 10 studied years (Flow x 31,536,000/Population).

Response - improvement in water-use efficiency in the basin in the studied period is estimated based on the improvements to the water-supply system in the studied period. The Motru river has, at its mouth, an annual average flow of $9.8 \mathrm{~m}^{3} / \mathrm{s}$ (2007) and $15.2 \mathrm{~m}^{3} / \mathrm{s}$ (2012), divided by a total basin population of 125,710 inhabitants (year 2002 basis) and 121,108 inhabitants (year 2007 basis) (Table 1).

Table 1. Water quantity parameters, levels, and scores (state,

\begin{tabular}{|c|c|c|c|}
\hline & Parameter & Level & Score \\
\hline State & $\begin{array}{c}\text { Basin water } \\
\text { availability } \\
\text { per capita } \\
\left(\mathrm{m}^{3} / \text { person year }\right) \\
\text { considering surface } \\
\text { water sources }\end{array}$ & $\begin{array}{c}\mathrm{Wa}<1,700 \\
1,700<\mathrm{Wa}<3,400 \\
3,400<\mathrm{Wa}<5,100 \\
5,100<\mathrm{Wa}<6,800 \\
\mathrm{Wa}>6,800\end{array}$ & $\begin{array}{l}0.00 \\
0.25 \\
0.50 \\
0.75 \\
1.00\end{array}$ \\
\hline Pressure & $\begin{array}{l}\Delta 1 \text {-variation in } \\
\text { the basin water } \\
\text { availability per } \\
\text { capita in the } \\
\text { studied period, } \\
\text { relative to the } \\
\text { long-term average } \\
\text { (2,662.66 } \mathrm{m}^{3} / \\
\text { person year) }\end{array}$ & $\begin{array}{c}\Delta 1<-20 \% \\
-20 \%<\Delta 1<-10 \% \\
-10 \%<\Delta 1<0 \% \\
0<\Delta 1<+10 \% \\
\Delta 1<+10 \%\end{array}$ & $\begin{array}{l}0.00 \\
0.25 \\
0.50 \\
0.75 \\
1.00\end{array}$ \\
\hline Response & $\begin{array}{l}\text { Improvement } \\
\text { in water-use } \\
\text { efficiency in the } \\
\text { basin, } \\
\text { in the studied } \\
\text { period }\end{array}$ & $\begin{array}{l}\text { Very poor } \\
\text { Poor } \\
\text { Medium } \\
\text { Good } \\
\text { Excellent }\end{array}$ & $\begin{array}{l}0.00 \\
0.25 \\
0.50 \\
0.75 \\
1.00\end{array}$ \\
\hline
\end{tabular}
pressure, and response).

(processed after Chavez and Alipaz, 2007) 


\section{Water Quality Sub-Indicator}

The following parameters were established in order to calculate the water quality sub- indicator (Table 2). State - basin long-term average BOD5 (mg/l), consists in establishing the average of the periods 2002-2007 and 2002-2012, the values being recorded at Fața Motrului hydrometric station. Pressure - $\Delta 2$ - variation of BOD5 within the basin river in the studied period related to the long-term average, results from the difference between the value of BOD5 recorded in 2007 and 2012, and the value in 2002. This difference is reported in percentage compared to the long-term average (10 years), which is considered as being $100 \%$. Response - improvement in adequate sewage treatment in the basin in the studied period is estimated based on the improvements of the sewage system.

\section{Environment Pressure Index (EPI): Development and Application}

Similar to the hydrology indicator, the environment indicator was computed as the average of its state, pressure, and response parameters (Table 3). State is the percentage of the basin area under natural vegetation $(\mathrm{Av})$, indicating the percentage of the area covered with natural vegetation out of the total area of the administrative units in the year when the study started (2002). Pressure is basin EPI (agriculture areas and urban population) in the studied period consists firstly in the difference between the percentage of natural vegetation area and urban population corresponding to the years 2007, 2012, and 2002. Furthermore, the index formula proposed by Chaves and Alvarez (2007) is applied (see Eq. 2). Response is evolution of the area under conservation (number and surface) in the studied period, is estimated based on data provided by the Ministry of Environment and Climate

Table 2. Water quality parameters, levels, and scores (state, pressure, and response).

\begin{tabular}{|c|c|c|c|}
\hline & Parameter & Level & Score \\
\hline \multirow{5}{*}{ State } & & BOD $>10$ & 0.00 \\
& Average long-term & $10<\mathrm{BOD}<5$ & 0.25 \\
& BOD5 & $5<\mathrm{BOD}<3$ & 0.50 \\
& within the basin (mg/l) & $3<\mathrm{BOD}<1$ & 0.75 \\
& & $\mathrm{BOD}<1$ & 1.00 \\
\hline \multirow{5}{*}{ Pressure } & $\Delta 2$-variation of BOD5 & $\Delta 2>20 \%$ & 0.00 \\
& within the basin in & $20 \%>\Delta 2>10 \%$ & 0.25 \\
& the studied period, & $0<\Delta 2<10 \%$ & 0.50 \\
& relative to the & $-10 \%<\Delta 2<0 \%$ & 0.75 \\
& long-term average & $\Delta 2<-10 \%$ & 1.00 \\
\hline \multirow{5}{*}{ Response } & Improvement in & Very poor & 0.00 \\
& sewage treatment/ & Poor & 0.25 \\
& disposal & Medium & 0.50 \\
& within the basin, in the & Good & 0.75 \\
& studied period & Excellent & 1.00 \\
\hline
\end{tabular}

(processed after Chavez and Alipaz, 2007)
Change - Natura 2000 [46] and the National Agency for Environmental Protection [47].

Life Quality Index (LQI):

Development and Application

The parameters of Life indicators are related to basin human life quality. Chavez and Alipaz [16] proposed the human development index, which is not applicable given the scale of the research area (LAU2), the lack of economic data, the high unemployment rate, and the high percentage of labor migration to Western Europe. Therefore, the present study used the formula proposed by Lazăr and Lazăr [28]; the indicators were calculated and there resulted LQI values for each administrative unit (2002, 2007, and 2012) (Fig. 2). Furthermore, LQI determination started from raw values concerning medical units, medical stuff, employees, supply of drinking water (thousands of $\mathrm{m}^{3}$ annually), wastewater treatment plants, and length of the sewage network.

The obtained results after the calculation of LQI were distributed in six value classes for an easier comparison in time: <0.024; 0.025-0.043; 0.044-0.060; 0.061-0.147; $0.148-0.398$; and $0.399-0.991$. The representative value class is $0.025-0.043$ (13 administrative units in 2002; 12 in 2007, and eight in 2012). In 2012, with not so many administrative units (8), the value class with the variation between 0.061-0.147 individualizes. At an overview, LQI variation in the Motru basin met significant increases both in the five years and in 10 years of study. In 2002, high values are met in the administrative units situated close to the main towns, such as Baia de Aramă, Motru, and Strehaia. In 2007 the growth of the standard of living is felt in the villages in Mehedinți county, in the middle basin of the Motru River (Ilovăt, Malovăţ, Şişeşti), and in 2002 the significant increases of LQI belong to the administrative units located between Motru and Baia de Aramă. This fact

Table 3. Environment pressure index parameters, levels, and scores (state, pressure, and response).

\begin{tabular}{|c|c|c|c|}
\hline \multirow{5}{*}{ State } & Parameter & Level & Score \\
\hline \multirow{5}{*}{ Pressure } & Percentage of the & $\mathrm{Av}<5$ & 0.00 \\
& basin area under & $10<\mathrm{Av}<10$ & 0.25 \\
& natural vegetation (Av) & $25<25$ & 0.50 \\
& & $\mathrm{Av}>40$ & 0.75 \\
& Basin EPI & $\mathrm{EPI}>20 \%$ & 0.00 \\
& (agriculture areas and & $20 \%<\mathrm{EPI}>10 \%$ & 0.25 \\
& urban population) in & $10 \%<\mathrm{EPI}<5 \%$ & 0.50 \\
& the studied period & $5 \%<\mathrm{EPI}<0 \%$ & 0.75 \\
& & $\mathrm{EPI}<0 \%$ & 1.00 \\
\hline \multirow{5}{*}{ Response } & Very poor & 0.00 \\
& Evolution in basin & Poor & 0.25 \\
& conservation areas in & Medium & 0.50 \\
& the studied period & Good & 0.75 \\
& & Excellent & 1.00 \\
\hline
\end{tabular}

(processed after Chavez and Alipaz, 2007) 

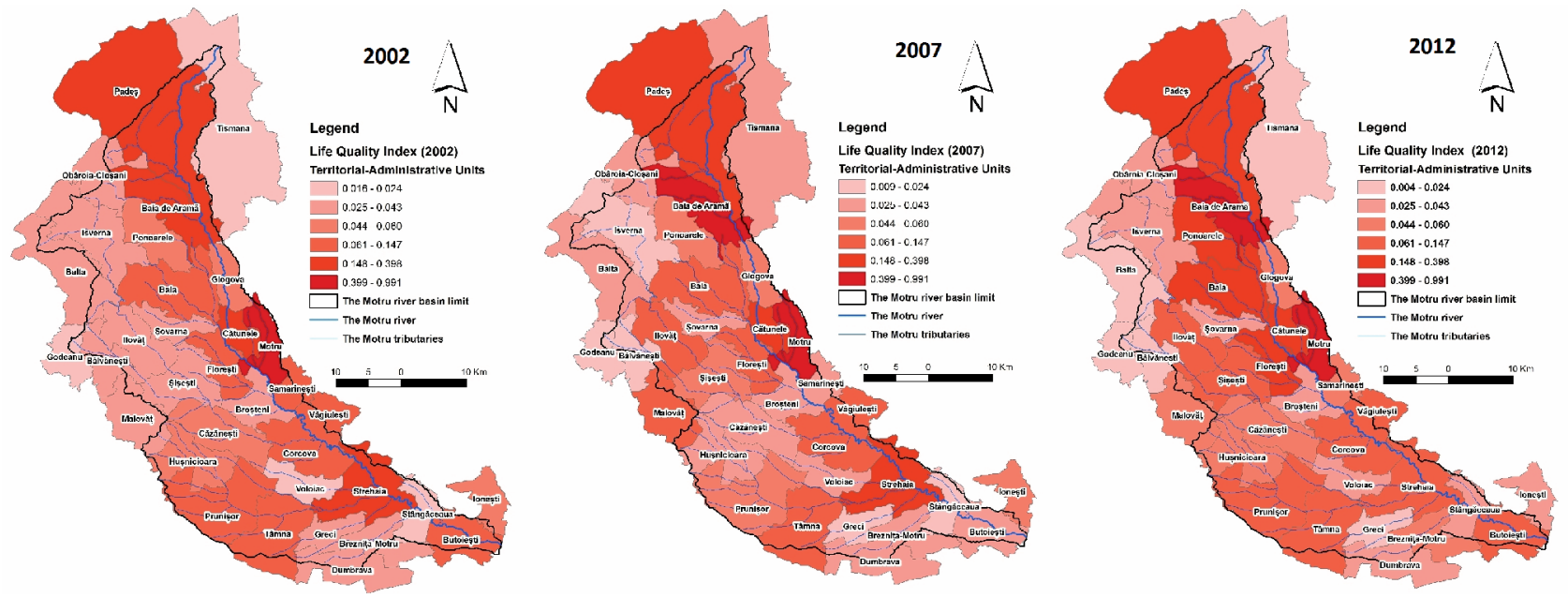

Fig. 2. Spatial and temporal distribution of life quality index (LQI) within the Motru River basin.

is due to the development of the water supply and sewage system in rural areas, which must meet the European standards; their establishment and modernization was possible through accessing European funds by local municipalities. In this regard, we can mention Bala (the construction of a wastewater treatment plant), Cătunele $\left(375,000 \mathrm{~m}^{3}\right.$ of drinking water in 2012, compared to the lack of this facility in 2002), and Floreşti $\left(35,000 \mathrm{~m}^{3}\right.$ supplied drinking water, a wastewater treatment plant, and $6.2 \mathrm{~km}$ of sewage network in 2012, compared to the previous years when it did not have all of these facilities).

Life quality index aggregation by levels and values of the three parameters is rendered in Table 4. State - LQI value in the year before the studied period, precisely the value from 2002 and 2007.

Table 4. Life quality index parameters, levels, and scores (state, pressure, and response).

\begin{tabular}{|c|c|c|c|}
\hline \multirow{5}{*}{ State } & Parameter & Level & Score \\
\hline \multirow{5}{*}{ Pressure } & LIFE - life quality & LQ $<0.1$ & 0.00 \\
& index value in the & $0.1<\mathrm{LQ}<0.3$ & 0.25 \\
& year before to the & $0.3<\mathrm{LQ}<0.6$ & 0.50 \\
& studied period & $0.6<\mathrm{LQ}<0.9$ & 0.75 \\
& LQ $>0.9$ & 1.00 \\
\hline \multirow{5}{*}{ Response } & Variation of & $\Delta<-20 \%$ & 0.00 \\
& the number of & $-20 \%<\Delta<-10 \%$ & 0.25 \\
& employees within the & $-10 \%<\Delta<0 \%$ & 0.50 \\
& basin, in the studied & $0<\Delta<+20 \%$ & 0.75 \\
& period, relative to the & $\Delta>+20 \%$ & 1.00 \\
& previous period & & \\
& Evolution of LQ & $\Delta<-10 \%$ & 0.00 \\
& Index within the & $-10 \%<\Delta<0 \%$ & 0.25 \\
& basin, in the period & $0<\Delta<+10 \%$ & 0.50 \\
& studied & $+10 \%>\Delta>+20 \%$ & 0.75 \\
& & $\Delta>20 \%$ & 1.00 \\
\hline
\end{tabular}

(adapted after Chavez and Alipaz, 2007; Lazăr and Lazăr, 2008)
Pressure - in the case of a life pressure parameter, it was considered as the variation of the employees during the studied period. Negative values of this parameter indicate that the population became poorer during the analyzed period, and vice-versa. Variation of the employees within the river basin, in the studied period relative to the previous period, took into account the number of the employees at the beginning of the period 2002-07 and at the end of the studied period 2007-12. Therefore, the percentage evolution and regression at period level was calculated (the percentage rendering the number of employees at the end of the period compared to the beginning of the period; it was subtracted from $100 \%$ in order to obtain the exact variation).

Response - evolution of LQI within the catchment area in the studied period consisted in calculating the LQI values from the beginning of the period (2002 and 2007) and also from its end (2007 and 2012). Then the percentage of evolution or regression was calculated at the period level (what percentage LQI represented at the end of the period compared to the beginning and the result was subtracted from $100 \%$ to find out the precise variation). Life response parameter is the percentage variation of LQI in the studied period relative to the previous value, which gives an indication of the evolution (positive or negative) of the life quality within the river basin.

\section{Policy, Education Index (EI): Development and Application}

The sub-indicators taken into account for the calculation of EI were selected from the online database of the National Institute of Statistics [45] and correspond to each local administrative unit for 2002, 2007, and 2012: schools, teachers, school population, libraries, and number of PCs (Fig. 3).

For a better statistic and graphical interpretation, EI values related to the administrative territorial units within the Motru basin were divided into six value classes: 

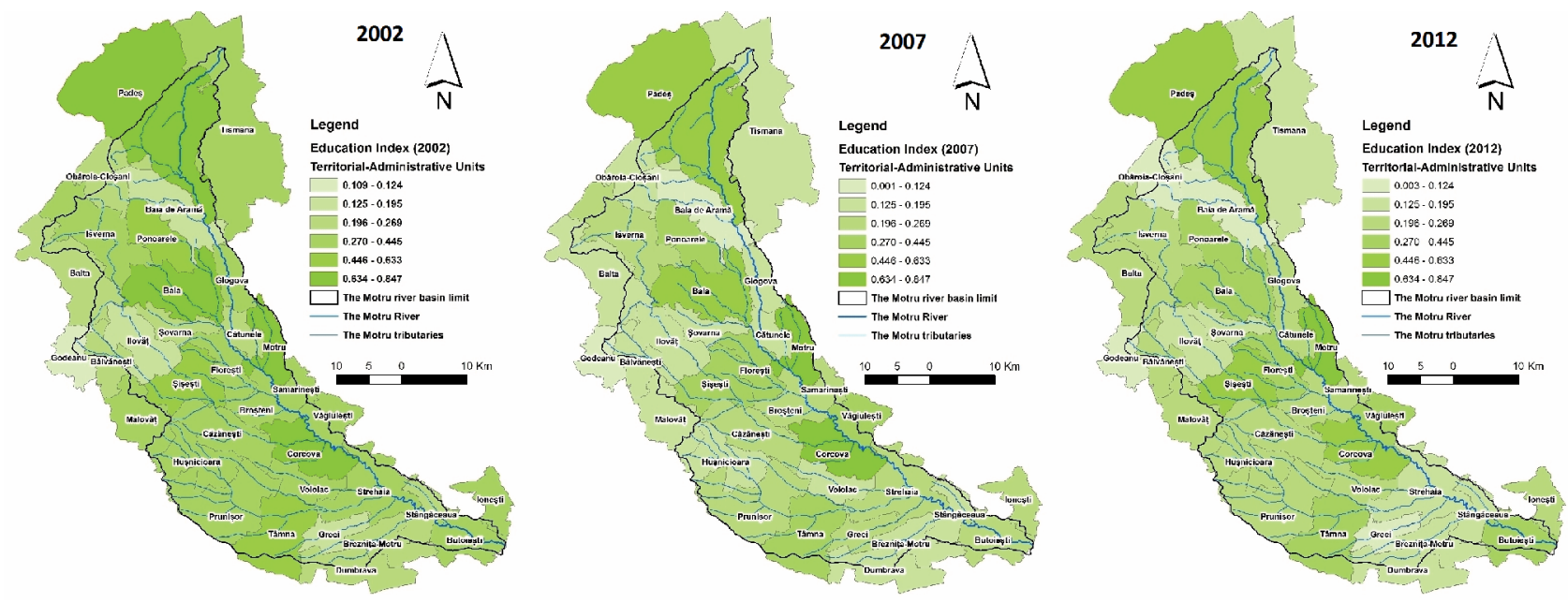

Fig. 3. Spatial and temporal distribution of education index (EI) within the Motru River basin.

$<0.124,0.125-0.195,0.196-0.269,0.270-0.445,0.446-$ 0.633 , and $0.634-0.847$.

In the studied period EI values were declining and this fact was proved even by the predominant value class: in 2002, 15 administrative territorial units corresponded to the value class $0.270-0.445$; in 2007 most administrative territorial units (12) had values between 0.125-0.195; in 2012 the values were reduced significantly, the administrative territorial units (13) being represented in the majority by the class $0.196-0.269$. EI has recorded high values, corresponding to the class 0.634-0.847 in 2002 and 2007 for Motru, Padeș, Bala, and Corcova (EI value 0.847 in 2002); and Motru and Corcova (EI value 0.731 in 2007). In 2012 this value class was not represented, the highest values being between $0.446-0.633$ and corresponding to Motru (EI value 0.633), Padeş, Corcova, and Şişeşti (the location that recorded progress in education - the EI value is 0.544 in 2012 in comparison with 0.500 in 2002).

The variation of the sub-indicators that were the starting point in determining values had an impact on the dynamics of local education. Thus, significant reductions were recorded at school level: schools (Motru: 16 in 2002 and only five in 2012; Strehaia: 15 in 2002 and only two in 2012), teachers (Motru: 346 in 2002 and only 283 in 2012; Strehaia: 177 in 2002 and only 128 in 2012), and pupils (Motru: 6,545 in 2002 and 5,022 in 2012; Strehaia: 2,724 in 2002 and 2,187 in 2012). The only sub-indicator that recorded an increase between 2002-12 is the number of PCs at the level of local administrative units, despite the fact that the river basin is predominantly rural. Urban surroundings recorded the highest increases: Motru (144 PCs in 2002 and 265 in 2012) and Strehaia (52 PCs in 2002 and 90 PC in 2012), adding also to these Florești (six PCs in 2002 and 51 PCs in 2012).

Determining EI as a weighted average of the scores of the three parameters was based on the steps described below; the resulted values are presented in Table 5 . State - EI value in the year before the studied period corresponds to the values calculated in the years 2002 and 2007. Pressure - variation of the pupils' number in the studied period relative to the previous period, represents the number of pupils registered at the beginning of the period (2002-07), and at the end of the studied period (2007-12); then the evolution or regression percentage (the percentage represented by the number of pupils at the end of the period compared to the beginning and the result subtracted from $100 \%$ to find out the exact variation) was calculated.

Response - evolution of EI is shown by the EI values from the beginning of the period (2002-07) and from the end of the period (2007-12). The percentage evolution or regression was calculated (what percentage EI value represented at the end compared to the beginning and the result was subtracted from $100 \%$ for an exact variation). The negative values for the two pressure and response parameters come to confirm once again the decrease in the number of inhabitants in the entire basin and demographic aging (these two are generated mainly by the decrease of the students' number and subsequently the decrease

Table 5. Education index parameters, levels, and scores (state, pressure, and response).

\begin{tabular}{|c|c|c|c|}
\hline \multirow{5}{*}{ State } & Parameter & Level & Score \\
\hline \multirow{5}{*}{ Pressure } & Education Index & EI $<0.1$ & 0.00 \\
& value in the year & $0.1<\mathrm{EI}<0.3$ & 0.25 \\
& before the studied & $0.3<\mathrm{EI}<0.6$ & 0.50 \\
& period & $0.6<\mathrm{EI}<0.9$ & 0.75 \\
& EI $>0.9$ & 1.00 \\
\hline \multirow{5}{*}{ Response } & Variation of the & $\Delta<-20 \%$ & 0.00 \\
& pupils' number in & $-20 \%<\Delta<-10 \%$ & 0.25 \\
& the studied period, & $-10 \%<\Delta<0 \%$ & 0.50 \\
& relative to the & $0<\Delta<+10 \%$ & 0.75 \\
& previous period & $\Delta>+10 \%$ & 1.00 \\
\hline & Education index & $-10 \%<\Delta<0 \%$ & 0.25 \\
& within the basin, in & $0<\Delta<+10 \%$ & 0.50 \\
& the studied period & $+10 \%>\Delta>+20 \%$ & 0.75 \\
& & $\Delta>20 \%$ & 1.00 \\
\hline
\end{tabular}

(adapted after Chavez and Alipaz, 2007; Lazăr and Lazăr, 2008) 
of schools). Since this indicator measures the population educational level, negative EI values would be correlated with the disability and unavailability of the population to become involved in the management of the river basin, putting more pressure on the decision-makers.

\section{Watershed Sustainability Index: Final Values}

The interpretation of the watershed sustainability index value is based on the $0-1$ range, with 1 being the most preferred and 0 the least preferred. The comparison of the final value can be done on a global scale, e.g., the performance of a basin is considered low if the final index of WSI is $<0.5$, intermediate if WSI is between 0.5 and 0.8 , and high if WSI is $>0.8$ [16]. By applying the previously presented methodology, the Motru basin obtained an overall WSI score of 0.36 (low sustainability) and 0.51 (intermediate sustainability). The watershed sustainability index is being applied to other basins in South America, Africa, and Oceania. The same intermediate level of basin sustainability was obtained for the F. Verdadeiro basin (southern Brazil) between 1996 and 2000 (WSI score was 0.65) [16]. For West Java, the WSI final value is considered poor, poor-medium, medium-good, or good if its value is $<25$, between 25 and 50 , between 50 and 75 , or between 75 and 100, respectively [17]. The interpretation of the sub-index and final index values has been linked to the level of priority of action. In this regard, the final values obtained for the Motru basin correspond to poormedium ( 0.36 for five years) and medium-good ( 0.51 for 10 years), which require high-medium and medium-low priority actions, respectively.

Tables 6 and 7 present the levels, scores, and overall WSI for the analyzed periods of five (2002-07) and 10 years (2002-12). The choice of the years of study takes into account the implementation stages of the Water Framework Directive [2] in Romania. The results are visible in the short term, to the achievement of the main objective, namely "good status" by 2015. The adaptation of the index proposed by Chavez and Alipaz [16] aims at changing the threshold values for level and score in case of life quality index and education index [28], thus resulting in an index of sustainability adaptive to the Romanian reality that can be easily extrapolated to any EU country. In the case of water quantity pressure parameter, the variation in Wa during the five-year studied period, with respect to the long-term average, was -53.43 . This resulted in a pressure score of 0.00 . In the case of quantity response, in the fiveyear considered period, there was some improvement in water use efficiency (extension of water supply systems and the construction of wastewater treatment plants) within the basin, which corresponds to a score of 0.25 and 0.5 (Table 1). Therefore, the averaged value of state, pressure, and response parameters for water quantity in the basin was 0.17 for five years and 0.67 for 10. Regarding the water quality sub-indicator, pressure corresponded to the variation in the BOD5 within the basin in the five-year period $(-1.96 \%)$ and in the 10 -year period $(-14.31 \%)$, yielding, according to Table 2, scores of 0.75 and 1.00 . The state parameter for quality (the basin BOD5 long-term average) was equal to $2.33 \mathrm{mg} / \mathrm{l}$ for five years and to $1.69 \mathrm{mg} / \mathrm{l}$ for 10 years. This resulted in a state score of 0.75 . The response for the water quality sub-indicator resulted in a score of 0.25 and 0.50 (poor improvement in sewage treatment/disposal in the studied five years and medium in the 10 -year period). The quality sub-indicator was therefore 0.58 and 0.75 . Hence, the overall hydrology indicator value is simply the average of the quantity and quality sub-indicators: 0.37 for the period 2002-07, five years; 0.71 for the period 2007-12, 10 years.

Concerning the environment pressure index, the combined basin variation (increase/decrease) in agricultural area and urban population in the studied period was 0.37 respectively, -0.34 . This corresponds to an environmental pressure score of 0.75 for five years and 1.00 for 10 years. In the case of environmental state, the basin had $28.28 \%$ and $28.47 \%$ of its original vegetation cover in the years 2002, respectively 2007, which resulted in a value of 0.75 and 1.00 . The environmental response (evolution in protected areas of surface and number) was poor and medium within the Motru basin, thus resulting in a score of 0.25 and 0.75 . Therefore, the overall score for the environment indicator was 0.58 (five years) and 0.75 (10 years).

Table 6. Levels and values of the parameters and the basin WSI (2002-07).

\begin{tabular}{|c|c|c|c|c|c|c|c|}
\hline & \multicolumn{2}{|c|}{ State } & \multicolumn{2}{|c|}{ Pressure } & \multicolumn{2}{|c|}{ Response } & \multirow{2}{*}{ Result } \\
\hline & Level \% & Score & Level & Score & Level & Score & \\
\hline \multirow[t]{2}{*}{ Hydrology } & $\begin{array}{c}2,554.48 \\
\mathrm{~m}^{3} / \text { person year }\end{array}$ & 0.25 & -53.43 & 0.00 & Poor & 0.25 & 0.17 \\
\hline & $2.33 \mathrm{mg} / 1$ & 0.75 & -1.96 & 0.75 & Poor & 0.25 & 0.58 \\
\hline Environment & 28.28 & 0.75 & 0.37 & 0.75 & Poor & 0.25 & 0.58 \\
\hline Life Quality & 0.105 & 0.25 & $-15.87 \%$ & 0.25 & $-0.44 \%$ & 0.25 & 0.25 \\
\hline Policy-Education & 0.369 & 0.5 & $-10.30 \%$ & 0.25 & $-28.72 \%$ & 0.00 & 0.25 \\
\hline Result & \multicolumn{6}{|c|}{$\mathrm{WSI}=(0.37+0.58+0.25+0.25) / 4=$} & 0.36 \\
\hline
\end{tabular}


Table 7. Levels and values of the parameters and the basin WSI (2002-12).

\begin{tabular}{|c|c|c|c|c|c|c|c|}
\hline & \multicolumn{2}{|c|}{ State } & \multicolumn{2}{|c|}{ Pressure } & \multicolumn{2}{|c|}{ Response } & \multirow{2}{*}{ Result } \\
\hline & Level \% & Score & Level & Score & Level & Score & \\
\hline \multirow{2}{*}{ Hydrology } & $\begin{array}{c}4,118.98 \\
\mathrm{~m}^{3} / \text { person year }\end{array}$ & 0.50 & 5.32 & 1.00 & Medium & 0.50 & 0.67 \\
\hline & -14.31 & 0.75 & $1.69 \mathrm{mg} / 1$ & 1.00 & Medium & 0.50 & 0.75 \\
\hline Environment & 28.47 & 0.75 & -0.34 & 1.00 & Medium & 0.5 & 0.75 \\
\hline Life Quality & 0.104 & 0.25 & $-12.79 \%$ & 0.25 & $16.07 \%$ & 0.75 & 0.42 \\
\hline Policy- Education & 0.263 & 0.25 & $-23.51 \%$ & 0.00 & $-27.91 \%$ & 0.00 & 0.17 \\
\hline Result & & & $=(0.71+0.7$ & $2+0.17)$ & & & 0.51 \\
\hline
\end{tabular}

The temporal dynamics of life and education indicators and their distribution at territorial level offers an overview to the following aspects:

- Motru scores high in the quality of life index while Baia de Aramă recorded an increase in living standards, a phenomenon also recorded by one of the adjacent administrative territorial units, namely Ponoarele (LQI: 0.054 in 2002 and 0.238 in 2012). The administrative units Bala, Cătunele, and Floreşti (located along the Motru in the middle sector) recorded increases in terms of life quality, having LQI values corresponding to the class $0.148-0.398$ in 2012.

- Baia de Aramă and Strehaia were characterized by low values of EI, Baia de Aramă: 0.194 (2002) and 0.105 (2012), and Strehaia: 0.408 (2002) and 0.175 (2012). There were only two rural cases characterized by an increase of the educational level in the entire river basin (the phenomenon was generated by the increasing number of teachers and computers).

The analysed aspects emphasize mainly the fact that in many of these administrative units (20 rural and four urban), significant progress was made in living conditions and regressions in the educational environment (ObârşiaCloşani, Isverna, and Şovarna in the middle basin and Greci, Breznița-Motru, and Stângăceaua in the lower basin). According to the dynamic evaluation of quality of life and education at the level of administrative units, a series of aspects must be taken into account as they have triggered problems and economic and cultural differences between different local communities, for instance the asymmetries between urban and rural areas: attracting European funds by town halls to equip schools and hospitals, extending water supply and sewage networks in rural areas, developing wastewater treatment plants in urban areas, ensuring the drainage of surface waters through restoration works, and organizing campaigns regarding pollution and protection of water resources.

\section{Conclusions}

The application of WSI links the socio-economic drivers to water resource pressures and the responses based on the Water Framework Directive to national legislation, while at the same time being a useful tool for land-use planning and decision-making in the area of water protection.

The conducted methods highlight the fact that life and policy sub-indicators of the global index need to be replaced for the Romanian river basins; the hardest decision in this regard was the establishment of the correspondents for per capita income and the basin institutional capacity in integrated water resource management. Therefore, new contributions prove their significance in the methodological advancement by the adaptive sub-indicators for each case study, depending on its features concerning demography, education level, and stage of development. Even though the research deviates from the classic formula of the Watershed Sustainability Index, by bringing to the same final value, comprised between 0 and 1, the employed method does not affect its application and provides comparative capability across cases. The advantages of the new watershed sustainability index (WSI) are numerous:

- WSI is available: the indicator data are available and easily accessible. They are collected and published on a routine basis and made available to the public (website of the National Institute of Statistics).

- WSI is understandable: indicators are easily understood by a wide range of nontechnical audiences, such as water availability per capita, urban population, life quality, and education level.

- WSI is relevant: indicators reflect changes in the management and activities in the watershed (decrease of the number of schools and improvement of water supply and sewage systems). They are able to measure changes over time (as proven by the variation in value for both periods of analysis of five and 10 years).

- WSI is integrative: indicators demonstrate connections among the environmental, social, and educational aspects of sustainability.

\section{Acknowledgements}

The author would like to kindly acknowledge the national and regional institutions that supplied important 
information from online statistical databases (The National Institute of Statistics and The Jiu Water Branch "Romanian Water" National Administration). She is also grateful to the reviewers for their helpful comments.

\section{References}

1. BRUNDTLAND G.H. Our Common Future WCED. Oxford University Press. Oxford. England, 16, 1987. Available online: http://www.un-documents.net/our-common-future. pdf (accessed on 17 March 2016).

2. Water Framework Directive. CEE. Common Implementation 2000.

3. NESS B., URBEL-PIIRSALU E., ANDERBERG S., OLSSON L. Categorizing tools for sustainability assessment. Ecol. Econ, 60, 498, 2007.

4. SINGH R.K., MURTY H.R., GUPTA S.K., DIKSHIT A.K. An overview of sustainability assessment methodologies. Ecol. Indic, 9, 189, 2009.

5. FARSARI Y., PRASTACOS P. Sustainable development indicators: an overview. Personal communication in the International Conference Citizens. Sustainable Development, Environment. Foundation for Mediterranean Cooperation. Athens. Greece. 2002.

6. BOLLO MANENT M., HERNÁNDEZ SANTANA J.R., MÉNDEZ LINARES A.P. The state of the environment in Mexico. Central European Journal of Geosciences, 6, 219, 2014. doi:10.2478/s13533-012-0172-1.

7. SPANGENBERG J.H. Reconciling sustainability and growth - criteria, indicators, policies. Sustain. Dev., 12, 74, 2004.

8. HERMANS L.M. An Approach to Support Learning from International Experience with Water Policy. Water Resour Manage, 25, 373, 2011. doi: 10.1007/s11269-010-9705-x.

9. ZARKESH M.M., KHEIRKHAH E.S., NAHID A. Degradation mitigation management of recreational watersheds by selecting the most suitable action plan based on multi-criteria decision-making methods. Polish Journal of Environmental Studies, 21 (5), 1481, 2012.

10. RUSSO T., ALFREDO K., FISHER J. Sustainable Water Management in Urban, Agricultural and Natural Systems. Water, 6, 3934, 2014. doi:10.3390/w6123934.

11. BORREGO-MARÍN M.M., RIESGO L. Measuring the Sustainability of Water Plans in Inter-Regional Spanish River Basins. Water, 8, (8), 342, 2016.

12. MAYS L.W. Water resources sustainability. McGraw-Hill Professional. New York. 2006

13. BRADEN J.B., JOLEJOLE-FOREMAN M.C., SCHNEIDER D.W. Humans and the Water Environment: The Need for Coordinated Data Collection. Water, 6, 1, 2014. doi:10.3390/w6010001.

14. SULLIVAN C. Calculating a water poverty index. World Dev., 30, 1195, 2002

15. United Nations, Policy Research Initiative - Indicators of Sustainable Development: Guidelines and Methodologies. Third edition. New York. 2007. Available online: http:// www.un.org/esa/sustdev/natlinfo/indicators/guidelines.pdf (accessed on 20 July 2016)

16. CHAVES H.M.L., ALIPAZ S. An integrated indicator based on basin hydrology, environment, life, and policy: the watershed sustainability index. Water Resour Manag, 21, (5), 883, 20017. doi: 10.1007/s11269-006-9107-2.

17. JUWANA I., MUTTIL N., PERERA B.J.C. Indicator-based water sustainability assessment-A review. SCI Total Environ,
438, 357, 2012. doi.org/10.1016/j.scitotenv.2012.08.093.

18. TIMMERMANS J. Interactive Actor Analysis for Rural Water Management in The Netherlands: An Application of the Transactional Approach. Water Resour Manage, 23, 1211, 2009. doi: 10.1007/s11269-008-9323-z.

19. DA CRUZ N.F., MARQUES R. A multi-criteria model to determine the sustainability level of water services. Water Asset Manag. Int., 9, 16, 2016.

20. LIVERMAN D., HANSON M., BROWN B., MERIDETH R. Global sustainability: toward measurement. Environ Manage, 12, 133, 1998.

21. MĂRGINEAN I. . Human Development Index. Romania in an international context. Life quality, 21, 44, 2010 [In Romanian].

22. UNDP. Human Development Report 2013 - Technical notes. Available online: http://hdr.undp.org/sites/default/ files/hdr_2013_en_technotes.pdf (accessed on 21 January 2016).

23. UNGUREANU A., GROZA O., MUNTELE I. Moldova Population, labor and human settlements in transition. Corson Publishing House. Iaşi. Romania. 2002 [In Romanian].

24. COCEAN P., ILOVAN O.R. Elements of sustainable development management. Geographia Napocensis, 2, 5, 2008.

25. BOȚAN C.N., ILOVAN O.R., POP A.M. The Geographical Region and the Desiderata of Sustainable Development. Romanian Review of Regional Studies, 1, 83, 2005.

26. IOJĂ C., PĂTROESCU M., NIȚĂ M., ROZYLOWICZ L., IOJA A., ONOSE D. Categories of residential spaces after their accessibility to urban parks - indicator of sustainability in human settlements. WSEAS Transactions on Environment and Development, 6, 307, 2010.

27. IOJĂ C., ROZYLOWICZ L., PĂTROESCU M., NIȚĂ M.R., ONOSE D.A., ANDREOPOULOU Z., VIAGGI D. Agriculture and Conservation in the Natura 2000 Network: A Sustainable Development. Agricultural and Environmental Informatics, Governance and Management: Emerging Research Applications IGI Global, 339, 2011

28. LAZĂR C., LAZĂR M. The quantification of the sustainable development at local level. WSEAS Transactions on Business and Economics, 5, 310, 2008.

29. IANOŞ I., PETRIŞOR A.I. Micro-scale geostatistical analysis of the level of development. Case study: mountainous and subcarpathian area of Ialomița hydrographic basin. Geographia Technica. Special issue, 47, 2010.

30. IANOŞ I., PETRIŞOR A.I., ZAMFIR D., CERCLEUX A.L., STOICA I.V., TĂLÂNGĂ C. In search of a relevant index measuring territorial disparities in a transition country. Romania as a case study. Die Erde - Journal of the Geographical Society of Berlin, 1, 69, 2013. doi: 10.12854/ erde-144-5.

31. BRADEN J.B., BROWN D., DOZIER J., GOBER P., MAIDMENT D.R., SCHNEIDER S.L., SCHULTZ P.W., SHORTLE J.S., SWALLOW S.K., WERNER C.M. Social science in a water observing system. Water Resour. Res. 45, (11), 1, 2009. doi: 10.1029/2009WR008216.

32. SCHNOOR J.L. Water Sustainability in a Changing World. In The 2010 Clarke Prize Lecture. National Water Research Institute: Fountain Valley. CA. USA. 2010. Available online:http://www.nwri-usa.org/ pdfs/2010ClarkePrizeLecture.pdf (accessed on 20 October 2016)

33. IONUŞ $\mathrm{O}$. The characteristics of the chemical flow within the Motru catchment area, south - west Romania. Central European Journal of Geosciences, 3, 39, 2011a. doi: 10.2478/ s13533-011-0006-6. 
34. The Cadastral Atlas of Waters within Romania. National Institute of Hydrology and Water Management. Bucharest. 1992 [in Romanian].

35. The Jiu River Management Plan, Jiu Water Branch (ABA Jiu) - 2015 [in Romanian]. Available online: http://www. rowater.ro/dajiu/default.aspx (accessed on 10 March 2016).

36. European Environment Agency. Corine Land Cover geodatabase on land cover, reference year 2012.

37. IONUŞ $O$. The assessment of human pressure on surface waters within the Motru catchment area. Oltenia regionRomania. Proceedings of 6-th International Scientific Conference. Global Changes and Regional Development. University of Sofia "St. Kliment Ohridksi". Sofia. Bulgaria, 1, 43, 2011b.

38. POPESCU L., ŞOŞEA C., IONUŞ O., BĂDIȚĂ A. Evaluation of human resources for the sustainable implementation of tourism in the South-West and NorthWest of Lower Danube. Annals of Valahia University of Targoviste, 14, 100, 2014.

39. UNESCO Hydrology for the Environment, Life and Policy HELP Paris. France (Brochure), 2005.

40. SPANGENBERG J.H., BONNIOT O. Sustainability indicators - a compass on the road towards sustainability.
Wuppertal Paper. Dortmund: Wuppertal Institute, 81, 1998.

41. OECD environmental indicators: development, measurement and use. Reference paper. Paris. France, 2003.

42. DĄBROWSKA J., BAWIEC A., PAWĘSKA K., KAMIŃSKA J., STODOLAK R. Assessing the Impact of Wastewater Effluent Diversion on Water Quality. Polish Journal of Environmental Studies, 26, (1), 9, 2017.

43. SAWYER D. Anthropic pressure index for Savanna regions. Brasilia. Brazil, 1997.

44. PERRET B. Social indicators. State of places and perspectives. The CERC Papers. Paris. 2002.

45. Romanian National Institute of Statistics (INSSE). Available online: http://statistici.insse.ro/shop/ (accessed on 7 January 2016).

46. Romanian Ministry of Environment, Water and Forests. Natura 2000. Available online: http://www.mmediu.ro/ categorie/arii-naturale-protejate/208 (accessed on 8 April 2016).

47. National Agency for Environmental Protection. Romania. Available online: http://www.anpm.ro/ (accessed on 8 April 2016). 